\title{
Medial Crease Formation in Unfavorable Subbrow Excision: Medial Crease in Subbrow Excision
}

\author{
Heeyeon Kwon ${ }^{1}$, \\ Eui Cheol Jeong ${ }^{1,2}$ \\ ${ }^{1}$ Department of Plastic and \\ Reconstructive Surgery, Seoul National \\ University College of Medicine, Seoul; \\ ${ }^{2}$ Department of Plastic Surgery, SMG- \\ SNU Boramae Medical Center, Seoul, \\ Korea
}

No potential conflict of interest relevant to this article was reported.
Background Various surgical techniques have been developed to address senile upper eyelids. Upper blepharoplasty has limited efficacy in natural periorbital rejuvenation for severe lateral hooding of the upper eyelids, as well as often producing a 'surprised look'. Subbrow excision is a popular method in East Asia for the correction of eyelid drooping, especially on the lateral side as periorbital rejuvenation. However, medial upper eyelid skin redundancy often tends to be undercorrected. Here, we present a few cases of revisional blepharoplasty, especially for medial crease formation, to improve aesthetic results.

Methods Five patients, for a total of 10 eyelids, who underwent revisional blepharoplasty from January 2011 to January 2015 after a previous subbrow excision, were included. Patients were dissatisfied with uncorrected excessive skin on the medial part of the upper eyelid after a previous subbrow excision; thus, they underwent revisional blepharoplasty for medial crease formation.

Results During the follow-up period, patients were aesthetically satisfied with the postoperative results. No patients suffered from any complications during the follow-up period.

Conclusions After a previous unfavorable subbrow excision, medial crease formation, via a very minimally invasive technique, could be a favorable option to improve patient satisfaction without postoperative complication or discomfort.

Keywords Blepharoplasty, Eyebrows, Eyelids

\section{INTRODUCTION}

With aging, senile upper eyelids present with excessive skin, eyelid drooping, vision interference, and dermatitis on the lateral canthal area. Various surgical techniques have been developed to solve this problem. Among them, upper blepharoplasty is a common method. Through upper blepharoplasty, the surgeon excises redundant

Received: Aug 23, 2015 Revised: Sep 25, 2015 Accepted: Sep 29, 2015 Correspondence: Eui Cheol Jeong Department of Plastic Surgery, Seoul Metropolitan Government Seoul National University Boramae Medical Center, 20 Boramae-ro 5-gil, Dongjak-gu, Seoul 07061, Korea.

E-mail: ejeong.md@gmail.com

Copyright @ 2015 The Korean Society for Aesthetic Plastic Surgery.

This is an Open Access article distributed under the terms of the Creative Commons Attribution Non-Commercial License (http://creativecommons.org/licenses/by-nc/3.0/) which permits unrestricted non-commercial use, distribution, and reproduction in any medium, provided the original work is properly cited. $\quad w w w . e-a a p s . o r g$ skin of the upper eyelids along the entire lids, making a supratarsal crease as double-eyelid fold, while correcting ptosis at the same time [1-6]. However, this technique has limited efficacy in natural periorbital rejuvenation for severe lateral hooding of the upper eyelids; upper blepharoplasty often produces a 'surprised look' $[7,8]$. Subbrow excision was first introduced by Parkes et al. [9] in the 1970s to improve upon the disadvantages of upper blepharoplasty by excising excessive skin, subcutaneous adipose tissues, and orbicularis oculi muscle along the lower border of the eyebrow. This method became popular in East Asian countries for the correction of eyelid drooping, especially on the lateral side as a periorbital rejuvenation. However, medial upper eyelid skin redundancy often tends to be undercorrected with unfavorable results from subbrow excision [10-12]. Here, we present a few cases of revisional blepharoplasty, especially for medial crease formation, to improve aesthetic results. 


\section{METHODS}

This study included five patients, for a total of 10 eyelids, who underwent revisional blepharoplasty at our clinic from January 2011 to January 2015 after a previous subbrow excision with or without upper blepharoplasty. Patients were dissatisfied with uncorrected excessive skin on the medial part of the upper eyelid after the previous operation. All patients generally expected the existing supratarsal fold and the supratarsal crease to run more medially. All surgeries were performed by a single surgeon (ECJ) at least 6 months after the previous surgery. Preoperative clinical photographs on the front view of the patients' eyes were taken for both documentation and future reference. At 6 months post-surgery, all patients were questioned on their aesthetic satisfaction, with four grades: excellent, good, fair, and poor.

\section{Operation method}

While patients were in a sitting position, the location of previous supratarsal crease was observed by opening and closing of the eyes. The new ideal crease was marked on the medial area of the eyelids, extending the previous crease medially by poking the skin with a pick several times. The new crease line was usually located between the medial canthus and medial limbus of the pupil. The horizontal length of the line was about $10 \mathrm{~mm}$ (Fig. 1). Once patients lay down in a supine position, local anesthesia was administered on the pretarsal lid, only on the incision line, with a $2 \%$ lidocaine/1:100,000 epinephrine solution. After the local anesthesia took effect, an incision was made down to the full dermis depth along the incision line. A part of orbicularis oculi muscle strip was removed, and then the levator aponeurosis layer above the superior border of the tarsus was exposed. A 6-0 Vicryl (Ethicon Inc., Somerville, NJ, USA) buried suture was used to create a union between the skin, tarsus, and aponeurosis at one site. The tarsal attachment added an extra secure anchor, and the dermal connection to the aponeurosis formed a new crease by keeping the pretarsal skin taut when eyes were open (Fig. 2). The incision sites were closed with a 7-0 Mersilk (Ethi-

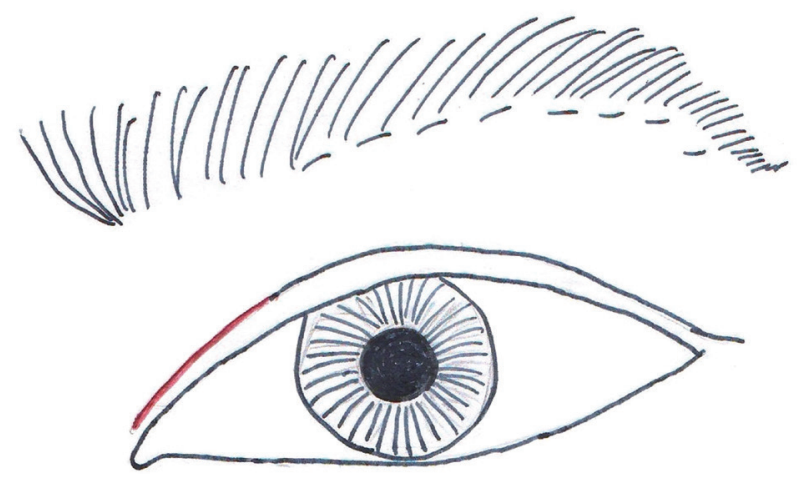

Fig. 1. The new horizontal crease line located between the medial canthus and medial limbus of the pupil. con Ltd, Edinburgh, UK) suture, following meticulous hemostasis. On the postoperative day 5 , the stitches were removed and edema had nearly completely subsided.

\section{RESULTS}

All patients were female, with a mean age of 51 years (range, 45-60 years). It was the second surgery for all patients. The average follow-up period was 10 months (range, 6-12 months). No patients suffered from any complications during the follow-up period. The aesthetic satisfaction was subjective in nature, judged by each patient's impression at the 6-month postoperative visit. Two patients rated their aesthetic improvement as excellent, and the other three rated their improvement as good. Of note, the one patient who received concomitant subbrow excision and upper blepharoplasty also expressed satisfaction. The surgeon also concurred with the patients' subjective rating results (Table 1, Fig. 3 and 4).

\section{DISCUSSION}

As people get older, the aging process shows on the eyelid, resulting in drooping and sagging eyelids [7]. Upper blepharoplasty is a classic method to improve these aging signs in the upper eyelids. In this technique, dermatochalasis is treated by an excision of the re-

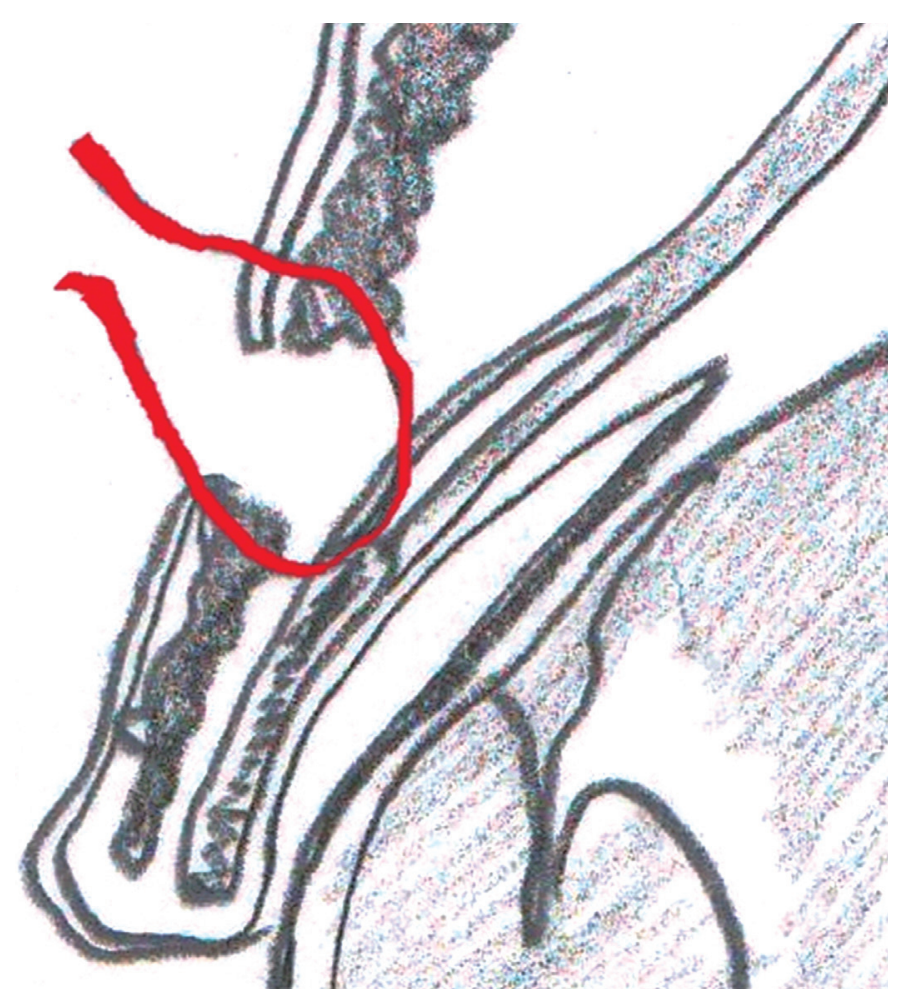

Fig. 2. The tarsal attachment added an extra secure anchor, and the dermal connection to the aponeurosis made a new crease by keeping the pretarsal skin taut when eyes were open. 
Table 1. Patient results

\begin{tabular}{llccc}
\hline Sex/age & \multicolumn{1}{c}{ Previous operation } & Follow-up period & Aesthetic satisfaction & Complication \\
\hline F/45 & Subbrow excision & 11 months & Good & None \\
F/47 & $\begin{array}{l}\text { Upper blepharoplasty (primary operation), subbrow excision } \\
\text { (secondary operation) }\end{array}$ & 6 months & Good \\
F/50 & Subbrow excision & 12 months & Excellent \\
F/53 & Concomitant subbrow excision and upper blepharoplasty & 9 months & Excellent & None \\
F/60 & Subbrow excision & 12 months & Good & None
\end{tabular}
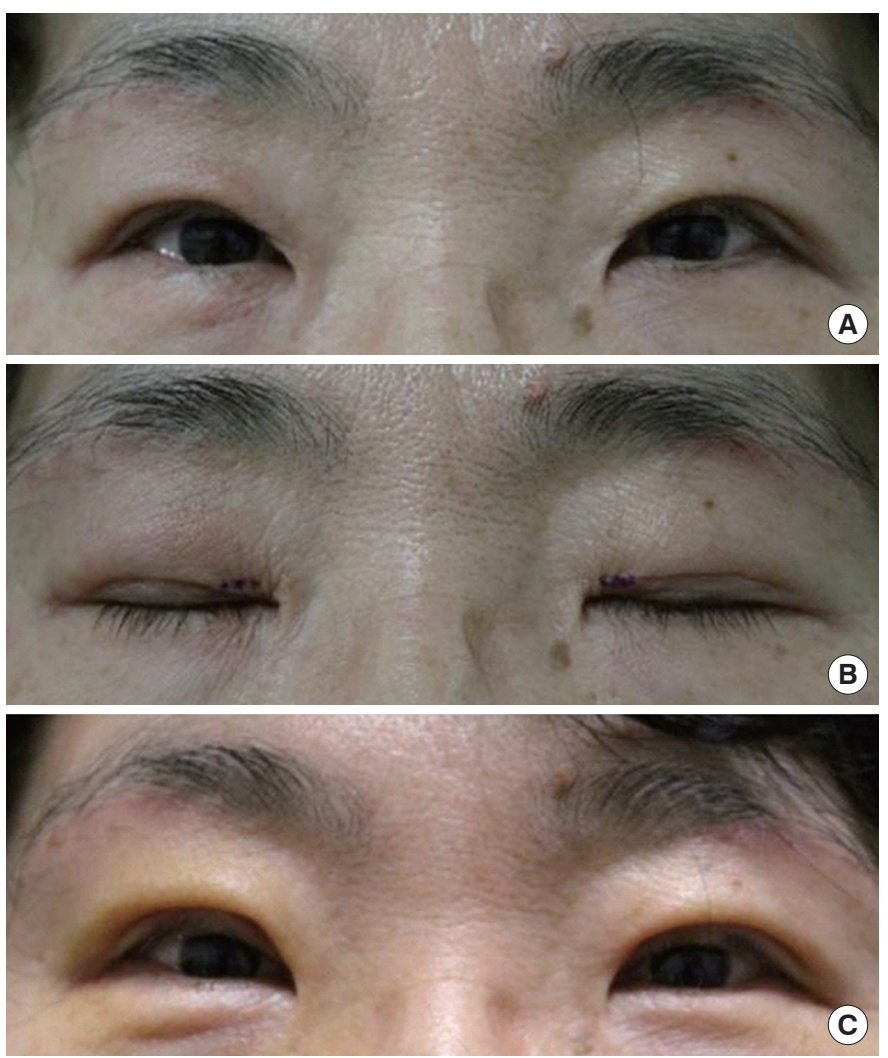

Fig. 3. (A, B) Preoperative photo of a 60 year-old woman. (C) Postoperative 5 day follow-up after medial crease formation. Postoperative edema almost subsided.

dundant skin and orbicularis oculi muscle. It is also possible to manipulate the aponeurosis structure through an incision along the upper eyelid crease [1,2,12-14]. However, the incision along the lid crease or supraciliary incision has numerous shortcomings in East Asian patients. It has been reported that an increase in the skin excision width is correlated with an unnatural appearance after the operation, because the thick upper eyelid skin is sutured to the lid crease line; this creates a prominent supratarsal fold that accentuates the overhanging appearance of the upper skin on the crease line [10].

To ameliorate the disadvantages of the upper eyelid blepharoplasty performed through the incision along the lid crease or su-
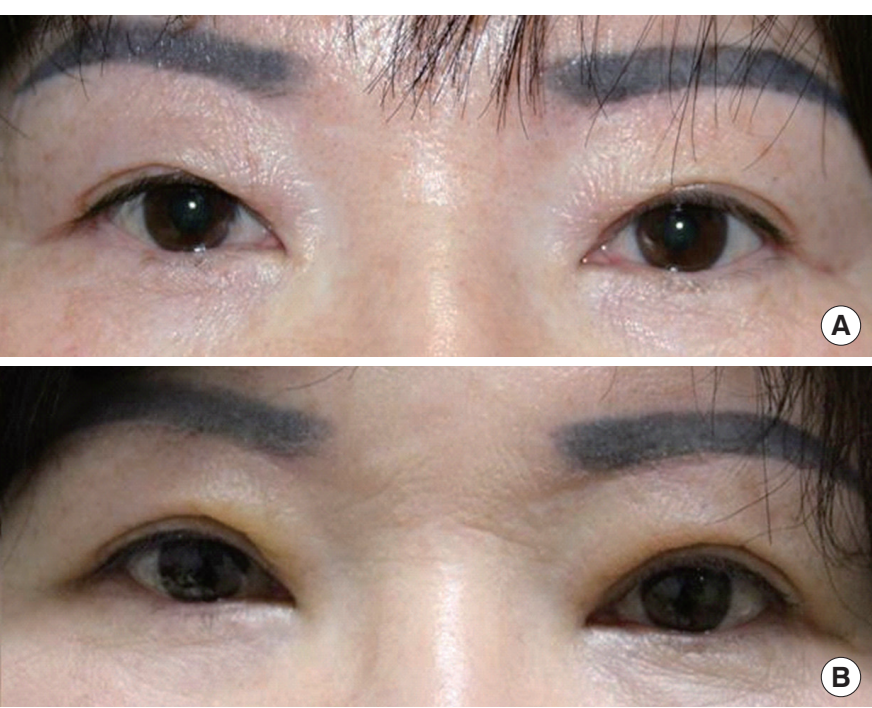

Fig. 4. (A) Preoperative photo of 50 year-old woman. (B) The 6 months follow-up after medial crease formation.

praciliary incision, subbrow excision has been popularly conducted in East Asian patients. Subbrow excision is now accepted as the primary procedure to correct the lateral hooding in selected patients. Several components cause lateral hooding of the upper eyelid skin, such as the dermatochalasis, thick upper eyelid skin with retro-orbicularis oculi fat (ROOF), bulky suborbicularis oculi muscles, brow ptosis, or prominent orbital rims [15]. Subbrow excision helps improve these conditions without dramatic changes of the facial appearance after the operation, such as a 'surprised look'. No conspicuous operative scars are produced in the lower lateral portion of the upper eyelid, and a more natural supratarsal crease is exposed by unfolding the hooding when the subbrow skin is removed. Some authors report that they fixate the orbicularis oculi muscle in the inferior flap via suture to the supraorbital rim periosteum at the margin of the upper flap, or add plication of the orbital septum in order to ensure the continuance of surgical results and to minimize the risk of relapse $[16,17]$.

However, subbrow excision also has some limitations. Drooping of the medial skin cannot be effectively corrected in patients with descending or flattening eyebrow, shortening of the distance between the eyebrow and lid margin, or severe skin sagging. To over- 
come this drawback, there are various operative designs in subbrow excision. Oh et al. [18] suggest a combination of two surgical approaches, subbrow excision and upper blepharoplasty, at the same time. Hara et al. [19] indicate a spindle-shaped incision line, with the widest amount of resected skin being determined on the vertical line crossing the center of the pupil. Occasionally, the undercorrection of medial skin drooping is encountered as a late complication during the follow-up period. For the cases presented here, the reason would be an underestimation of design in the primary surgery and the patient's new desire for a supratarsal crease. In the revision cases, or in some primary surgery cases, the authors also prefer the subbrow excision concomitantly with the upper blepharoplasty skin excision to form the supratarsal crease or repair the aponeurotic blepharoptosis. This combination method results in a more natural crease appearance, because the thin supraciliary skin is better preserved after subbrow excision rather than after the removal of redundant upper eyelid skin only by upper blepharoplasty incision. Conducting concomitant surgeries, however, could result in undercorrection, especially since the supratarsal crease hides under the medial redundant skin. To improve this medial appearance, most patients want to extend their supratarsal crease more medially. In fact, by poking the dropped medial skin with a pick several times, an acceptable crease could be chosen in all cases. Instead of additional skin excision, the authors made a medial crease in the poked line via a buried suture between the skin, tarsus, and aponeurosis. This was a very minimally invasive technique; postoperative edema subsided within 5 days in all cases. However, there are some limitations to consider. This technique is not able to be the sole procedure for patients who have a prominent epicanthal fold and no adequate supratarsal fold by the poking procedure preoperatively.

Patient satisfaction in correcting senile upper eyelids is best achieved when the possible result of the surgery is accurately predicted. By combining the advantages of blepharoplasty and subbrow excision, it was possible to correct the lateral drooping of the eyelids, to conceal the scar, and to address medial eyelid drooping without the risk of postoperative unnatural look. After subbrow excision, medial crease formation with a very minimally invasive technique could be a favorable option to improve patient satisfaction without postoperative complication or discomfort.

\section{PATIENT CONSENT}

Patients provided written consent for the use of their images.

\section{REFERENCES}

1. de la Torre JI, Martin SA, De Cordier BC, et al. Aesthetic eyelid ptosis correction: a review of technique and cases. Plast Reconstr Surg 2003; 112:655-60

2. Carraway JH, Tran P. Blepharoplasty with ptosis repair. Aesthet Surg J 2009;29:54-61.

3. Rohrich RJ, Coberly DM, Fagien S, et al. Current concepts in aesthetic upper blepharoplasty. Plast Reconstr Surg 2004;113:32e-42e.

4. McCurdy JA Jr. Upper blepharoplasty in the Asian patient: the "double eyelid” operation. Facial Plast Surg Clin North Am 2005;13:47-64.

5. Karam AM, Lam SM. Management of the aging upper eyelid in the asian patient. Facial Plast Surg 2010;26:201-8.

6. Kim DW, Bhatki AM. Upper blepharoplasty in the Asian eyelid. Facial Plast Surg Clin North Am 2007;15:327-35.

7. Hwang K, Kim DJ, Kim SK. Does the upper eyelid skin become thinner with age? J Craniofac Surg 2006;17:474-6.

8. Murakami M, Hyakusoku H. Treatment of upper eyelid dermatochalasis by resection of excess skin at the inferior margin of the eyebrow. J Nippon Med Sch 2008;75:364-6.

9. Parkes ML, Kamer FM, Merrin ML. Infrabrow lift. Laryngoscope 1976; 86:1869-72.

10. Kim YS, Roh TS, Yoo WM, et al. Infrabrow excision blepharoplasty: applications and outcomes in upper blepharoplasty in Asian women. Plast Reconstr Surg 2008;122:1199-205.

11. Lee D, Law V. Subbrow blepharoplasty for upper eyelid rejuvenation in Asians. Aesthet Surg J 2009;29:284-8.

12. Sugamata A, Yoshizawa N. Infraeyebrow excision blepharoplasty for Japanese blepharochalasis: review of 35 patients over 60 years old. Scand J Plast Reconstr Surg Hand Surg 2010;44:17-20.

13. Martin JJ Jr. Upper eyelid blepharoplasty with ptosis repair by levator aponeurectomy. JAMA Facial Plast Surg 2015;17:224-5.

14. Martin JJ Jr. Ptosis repair in aesthetic blepharoplasty. Clin Plast Surg 2013;40:201-12.

15. Pottier F, El-Shazly NZ, El-Shazly AE. Aging of orbicularis oculi: anatomophysiologic consideration in upper blepharoplasty. Arch Facial Plast Surg 2008;10:346-9.

16. Widgerow AD. Upper blepharoplasty with lateral segmental orbicularis excision. Ann Plast Surg 2003;50:471-4.

17. Har-Shai Y, Hirshowitz B. Extended upper blepharoplasty for lateral hooding of the upper eyelid using a scalpel-shaped excision: a 13-year experience. Plast Reconstr Surg 2004;113:1028-35.

18. Oh HY, Lee IH, Hong SC, et al. Combined subbrow excision with upper blepharoplasty using a tadpole shaped excision for blepharochalasis. Arch Aesthetic Plast Surg 2015;21:7-11.

19. Hara T, Hara T, Narita M, et al. Infero-eyebrow blepharoplasty for the upper eyelids of elderly patients. Br J Ophthalmol 2011;95:109-11. 